\title{
DASAR PEMIKIRAN ARSITEKTUR HUMANISTIK: PEMAHAMAN DAN TOKOHNYA DARI ERA KE ERA
}

Muhammad Nur Hakimuddin At-Toyibi

Magister Arsitektur Universitas Gadjah Mada e-mail: didinhakim94@mail.ugm.ac.id

\section{Syandy Diantrisna Kusuma}

Magister Arsitektur Universitas Gadjah Mada e-mail: syandy.diantrisna@mail.ugm.ac.id

\begin{abstract}
ABSTRAK
Arsitektur selalu berkembang sejalan dengan perkembangan zaman. Akan tetapi dengan berjalan dan berkembangnya zaman banyak dasar-dasar konsep rancangan arsitektur yang hanya memenuhi tuntutan klien atau mengedepankan aspek estetika saja. Pemahaman yang demikian mengacuhkan hal penting dalam rancangan arsitektur yang seharusnya mempertimbangkan manusia sebagai pengguna dari bangunan yang dirancang. Dengan latar belakang demikian perlu adanya kajian kembali tentang arsitektur humanistik sehingga dapat dijadikan dasar dalam rancangan arsitektur yang bisa memenuhi kebutuhan dasar manusia sebagai penggunanya. Tujuan dari penelitian ini adalah mengulas kembali arsitektur humanistik sehingga pemahaman arsitektur humanistik dapat hadir sebagai pertimbangan dalam merancang di era sekarang. Penelitian ini menggunakan metode studi literatur atau literature review dari tulisantulisan yang telah ada. Kajian ini menghasilkan kesimpulan pentingnya dasar pemikiran arsitektur humanistik sebagai landasan pertimbangan dalam rancangan.
\end{abstract}

KATA KUNCl: arsitektur humanistik; rancangan arsitektur

\section{LATAR BELAKANG}

Arsitektur sebagai wadah yang memfasilitasi beragam aktivitas dan kegiatan manusia seharusnya mempertimbangkan aspek kemanusiaan sebagai landasan dasar dalam perancangannya. Namun memprihatinkan karena tidak sedikit arsitek yang merancang arsitektur tanpa mempertimbangkan aspek manusia dalam desain. Aspek estetika, teknologi dan tuntutan klien justru lebih diutamakan dibanding pertimbangan kebutuhan manusia sebagai pengguna desain.

Taisto H. Makela dalam tulisannya menyimpulkan bahwa pada dasarnya bangunan yang baik adalah bangunan yang dapat sepenuhnya mengakomodasi kebutuhan fungsi yang diperlukan oleh pengguna. Keindahan dapat terbentuk dalam suatu bangunan ketika bangunan tersebut dapat berfungsi secara sempurna dan memberikan kenyamanan bagi penggunanya, sebagaimana ungkapan Socrates yang mengatakan "let us assume that whatever is useful is beautiful" (Makela, 2017: 12).

Oleh karena itu perlu adanya pertimbangan aspek kemanusiaan dalam sebuah rancangan arsitektur untuk mengimbangi nilai-nilai estetika maupun tuntutan klien. Teori arsitektur humanistik memiliki peran dalam hal ini. Arsitektur Humanistik pada dasarnya adalah konsep arsitektural yang menjadikan manusia sebagai tujuan utama dalam desain arsitektur.

Menurut $\mathrm{KBBI}$, kata Humanisme berawal dari kata humus yang berarti tanah atau bumi yang kemudian muncul kata homo yang berarti manusia dan humanus yang berarti sifat membumi atau manusiawi. Humanisme manganggap manusia atau individu rasional menduduki tingkat tertinggi dan sebagai tujuan dan nilai akhir ${ }^{1}$. Secara sederhana, humanis bisa dimaknai sesuatu yang berhubungan dengan manusia. Karenanya, pendekatan humanis merupakan pendekatan manusiawi atau yang berfokus pada dimensi manusianya ${ }^{2}$. Dalam arsitektur dapat diterjemahkan bahwa sifat manusiawi merupakan asas yang dijadikan sebagai dasar pertimbangan dalam keputusan konsep-konsep arsitektural.

Dengan latar belakang permasalahan di atas, dalam artikel ini dibahas mengenai arsitektur humanistik. Menurut penulis pembahasan arsitektur humanistik menjadi penting karena perlunya pemahaman dan kesadaran arsitek sebagai perancang terhadap aspek kemanusiaan atau Humanisme dalam merancang sebuah arsitektur. Pemahaman konsep-konsep dasar arsitektur

\footnotetext{
${ }^{1}$ https://kbbi.web.id/ (diakses: Senin, 28 Oktober 2019)

${ }^{2}$ http://berkota.co/2018/05/07/pendekatan-humanisdalam-pembangunan-dan-penataan-ruang-perlukah/ (diakses: Senin, 28 Oktober 2019)
} 
humanistik akan melahirkan sebuah rancangan yang memiliki nilai-nilai berimbang antara aspek kemanusiaan, estetika dan tuntutan lainnya. Dengan demikian hasil bangunan yang tercipta akan menjadi maksimal, baik dari aspek fungsinya sebagai wadah aktivitas manusia sebagai pengguna, maupun aspek keindahan yang akan menjadi nilai lebih dalam sebuah rancangan.

\section{KAJIAN TEORI}

\section{Teori Kebutuhan Manusia Abraham Maslow}

Abraham Maslow memiliki teori terkait kebutuhan manusia yang dikenal dengan "Maslow's Hirarchy of Needs". Maslow menggambarkan hirarki kebutuhan manusia dalam diagram piramida (Aruma \& Hanachor, 2017: 15). Semakin keatas maka manusia akan mencapai tujuan kebutuhan yang lebih tinggi. Teori ini dapat diadaptasi untuk konsep arsitektur (Goble, 1985: 25).

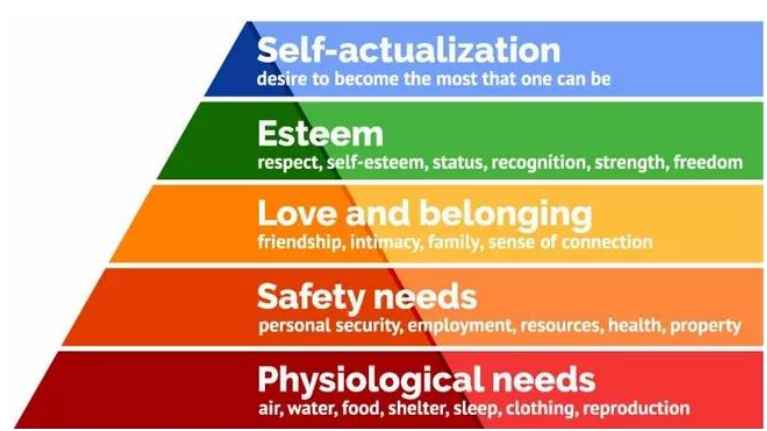

Gambar 1: Maslow's Hirarchy of Needs Pyramid sumber: https://www.simplypsychology.org/maslow.html

Adapun penjelasan hirarki kebutuhan manusia menurut Maslow dalam International Journal of Development and Economic Sustainability (2019:1922) yang disusun oleh Aruma dan Hanachor adalah sebagai berikut:

1. Kebutuhan Fisiologi (Physiological Needs)

Tingkat ini merupakan kebutuhan dasar yang terdapat pada peringkat paling bawah meliputi kebutuhan sandang, pangan dan papan (Goble, 1985: 43). Kebutuhan fisiologi adalah aspek terpenting yang harus terpenuhi dalam kehidupan manusia. Semua manusia berhak mendapatkan pemenuhan yang layak terhadap lebutuhan ini dikarenakan kebutuhan dasar yang tidak terpenuhi akan mempengaruhi kehidupan tiap individu. (Aruma \& Hanachor, 2017: 19-20)

2. Kebutuhan Keamanan (Safety Needs)

Kebutuhan ini menekankan pada rasa aman, tentram, dan jaminan bagi seseorang dalam melakukan aktivitas. Rasa aman yang terjamin akan memberikan kenyamanan lebih terhadap kehidupan manusia. (Aruma \& Hanachor, 2017: 20-21)
3. Kebutuhan Percaya dan Cinta Kasih (Belongingness \& Love Needs)

Kebutuhan ini merujuk pada kebutuhan manusia untuk dicintai dan dipercaya agar mendapatkan ketenangan dalam hidupnya. Rasa cinta dan percaya mencakup aspek yang luas seperti kedekatan dan penerimaan lingkungan terhadap masing-masing individu (Goble, 1985: 64). Kepercayaan dan cinta kasih yang didapatkan oleh tiap individu akan menumbuhkan rasa percaya diri dalam mengambil setiap keputusan. (Aruma \& Hanachor, 2017: 21)

4. Kebutuhan untuk Dihargai (Esteem Needs) Kebutuhan ini mengarah pada jenjang atau capaian seseorang dalam bidang pekerjaan tertentu. Pada tingkatan ini manusia membutuhkan capaian tertentu untuk menunjukkan derajatnya dalam lingkungan. Penghargaan diri dapat berasal dari dalam diri (internal individu) dan dari luar (pengakuan lingkungan). Dangan dihargai, seorang individu akan memberikan timbal balik yang positif pada lingkungannya. (Aruma \& Hanachor, 2017: 21)

5. Kebutuhan Akutualisasi Diri (Self Actualization) Pada tingkatan ini yang merupakan tingkatan terakhir dan tertinggi, kebutuhan mengarah pada keinginan seseorang untuk mengembangkan kapasitas kerjanya dengan baik yang seringkali nampak pada hal-hal yang sesuai untuk mencapai citra dan cita diri seseorang (Aruma \& Hanachor, 2017: 22). Pada tingkatan ini juga manusia sudah berfikir lebih jauh bagaimana bisa meningkatkan produktivitas kerjanya pada tahapan yang lebih tinggi (Goble, 1985: 87).

David Lester dalam penelitiannya melakukan pengukuran tingkat kebutuhan manusia menurut Abraham Maslow dalam skor nilai dan skala likert. Hasilnya membuktikan kejelasan teori yang dibangun Maslow tentang kebutuhan manusia, bahwasanya diantara 5 hirarki kebutuhan yang ditetapkan oleh Maslow, kebutuhan fisiologi memiliki nilai yang paling menunjukkan kesesuaian dengan kebutuhan dasar manusia (Lester, 2017: 15-17).

Dengan demikian kebutuhan fisiologi terbukti harus benar-benar terpenuhi bagi tiap individu. Jika kebutuhan dasar ini sudah terpenuhi, maka manusia dapat melangkah pada pemenuhan kebutuhan tingkat selanjutnya. Jika kebutuhan fisiologi yang merupakan kebutuhan dasar tidak terpenuhi, maka akan menyebabkan ketidaktenangan dalam hidup manusia (Lester, 2017: 17).

Hirarki kebutuhan manusia menurut Maslow di atas dapat dijadikan dasar dalam konsep arsitektur. Telaah kebutuhan manusia pada tingkat tertentu akan menghasilkan teori atau desain arsitektural yang berbeda pula. 


\section{METODE PENELITIAN}

Penelitian ini menggunakan metode kajian literatur atau literature review. Penulis berusaha mencari penelitian dan tulisan-tulisan yang berkaitan dengan tema pemikiran arsitektur humanistik, kemudian mengkomparasikan tulisan-tulisan tersebut sehingga membentuk susunan pemahaman tentang dasar pemikiran arsitektur humanistik. Kesimpulan dari tulisan ini dapat dijadikan bahan untuk memahami bagaimana aspek kemanusiaan harus menjadi perhatian dalam merancang arsitektur.

\section{HASIL PENELITIAN}

\section{Adaptasi Teori Kebutuhan Manusia Abraham Maslow dalam Arsitektur.}

Dalam sebuah tulisan, Alejandro Salado dan Roshanak Nilchiani melakukan pengadaptasian teori kebutuhan manusia Abraham Maslow ke dalam konsep arsitektural. Mereka menerjemahkan 5 hirarki kebutuhan manusia yang dibangun Maslow ke dalam bahasa yang berbeda (Salado \& Nilchiani, 2013: 928930), kemudian terbentuklah istilah kebutuhan baru agar lebih dekat dengan konteks arsitektur, meliputi kebutuhan fungsional, kebutuhan pelaksanaan, kebutuhan ketersediaan, kebutuhan efektifitas, dan kebutuhan adaptasi (Salado \& Nilchiani, 2013: 931).

Alejandro Salado dan Roshanak Nilchiani menerapkan pemikirannya tersebut dalam desain arsitektural. Konsep yang matang dengan pertimbangan hirarki kebutuhan manusia akan menciptakan sistem arsitektural yang dapat memenuhi kebutuhan penggunanya (Salado \& Nilchiani, 2013: 933-935).

Alejandro menyimpulkan dalam tulisannya bahwa struktur sistem yang dibentuk berdasarkan teori hirarki kebutuhan manusia Maslow dapat menghasilakn desain arsitektural yang sempurna dan dapat mengakomodasi kebutuhan pengguna. Makna dari hirarki kebutuhan manusia dapat menumbuhkan alternatif-alternatif baru dalam desain (Salado \& Nilchiani, 2013: 935).

Sayed Javad dalam tulisannya mengatakan bahwa kepuasan individu dari kebutuhan dasar berdasarkan teori hirarki kebutuhan manusia menunjukkan strata sosial tiap individu dalam masyarakat. Teori Maslow ini menujukkan perbedaan level kebutuhan manusia dari aspek-aspek yang tangible, sehingga teori ini yang berfokus pada jati diri tiap manusia harus ditelaah kembali dengan tinjauan yang lebih luas (Zavei \& Jusan, 2010: 313). Sayed Javad menempatkan teori hirarki kebutuhan manusia Maslow pada konteks penataan perumahan.
Dengan adanya teori hirarki kebutuhan manusia, hunian dapat dibedakan mejadi 3 yaitu shelter, house dan home. Istilah home memiliki derajat tertinggi karena memiliki susunan struktur yang lebih kompleks (Zavei \& Jusan, 2010: 314).

Hasil penelitian Sayed Javad memiliki kesamaan dengan argumen awal penulis bahwasanya mengabaikan kebutuhan dasar manusia sebagai pengguna hunian ataupun dalam rancangan lainnya dapat menyebabkan ketidakpuasan dan ketidakcocokan hasil desain dengan penggunanya. Permasalahan ini merupakan fenomena yang selalu terjadi dalam rancangan hunian. Seorang arsitek seharusnya mencari data yang sebenarnya terkait kebutuhan pengguna bangunan. Teori hirarki kebutuhan manusia menurut Abraham Maslow dapat menjadi dasar dalam menelusuri data-data yang dibutuhkan oleh arsitek untuk merancang (Zavei \& Jusan, 2010: 318).

\section{Pemahaman Arsitektur Humanistik Era Modern}

Mengutip pernyataan Frank Lloyd Wright bahwasanya "Arsitektur adalah semangat hidup kreatif yang luar biasa yang dari generasi ke generasi, dari zaman ke zaman, mempertahankan hasil ciptaan yang sesuai dengan sifat manusia, dan keadaannya saat mereka berubah. Itu adalah arsitektur yang sebenarnya" (Dreki, 2016: 3). Dari pernyataan tersebut dapat dipahami bahwasanya prinsip arsitektur pada dasarnya mempertimbangkan aspek manusia yang senantiasa berubah dan berkembang dari masa ke masa dikarenakan arsitektur selalu terhubung dengan kehidupan manusia.

Pada era modern terjadi Revolusi Industri yang membawa banyak ide dan kebutuhan baru bagi manusia. Perkembangan teknologi dan sains pun menuntut arsitektur untuk membentuk ekspresi dan artikulasi yang baru. Pandangan bahwasanya kehidupan di perkotaan yang memberikan jaminan lebih baik akan menyebabkan terjadi migrasi dari desa ke kota-kota yang mengakibatkan kepadatan yang tidak sesuai dengan daya tampung kota (Sennott, 2004: 56). Kemudian mulai tumbah permasalahan polusi dan masalah lingkungan lainnya. Disinilah arsitektur dengan adaptasinya terhadap teknologi dan sains memiliki peran untuk mengakomodasi perubahan yang terjadi pada kehidupan manusia (Dreki, 2016: 7).

Pada era moderen pula, pada akhir abad 18 dan pada abad 19, humanisme masuk ke tahap yang radikal dimana pemahaman humanisme berpaling dari agama yang berawal dari konflik antara ilmu 
pengetahuan dan agama karena inkonsitensi antara Darwinisme dan pembacaan Injil oleh kaum fundamentalis. Pada masa ini Humanisme diasosiasikan dengan Atheisme dan Agnostisisme yang kemudian menjadi aliran Humanisme ilmiah (scientific humanism) dengan prinsip bahwa segala macam permasalahan dapat diatasi dengan metode ilmiah. Pada abad 20 Humanisme modern mengalami perkembangan dan memunculkan paham baru seperti Humanisme religius, Humanisme sekuler, dan Humanisme baru (Sudradjat, 2010: 3).

Perkembangan pada era modern banyak menimbulkan dampak destruktif karena tidak mempertimbangkan aspek kemanusian. Dari sinilah muncul pemikiran tokoh Humanisme bernama Mario Rodriguez Cobos dari Argentina yang menilai tinggi kebebasan manusia dan upaya perjuangan melawan segala bentuk diskriminasi dan kekerasan. Diyakini olehnya bahwa perubahan di dunia sosial tidak mungkin terjadi tanpa dibarengi perubahan nilai, keyakinan dan tindakan pada tingkat individu. Kebebasan individu akan ditentukan oleh kondisi masyarakat di mana individu tersebut berada (Sudradjat, 2010: 4).

Perkembangan arsitektur dan Humanisme pada awal era modern masih dipengaruhi Antropomorfisme atau transkripsi tubuh manusia dalam bentuk bangunan. Hal ini di kritik oleh Geoffrey Scott pada tahun 1914 yang mengatakan bahwasanya arsitektur dan Humanisme saat itu hanya mengambil aspek fisik dari tubuh manusia. la beranggapan bahwa Humanisme dalam arsitektur harus lebih mempertimbangkan aspek prinsip tubuh secara psikologis (Sudradjat, 2010: 4). Pemahaman Scott ini relevan dengan teori Maslow dalam memenuhi kebutuhan manusia.

Selain Goeffrey Scott, Rudolf Wittkower menerjemahkan Humanisme dan arsitektur dalam struktur dan dasar geometri sehingga dapat membentuk "symphonic quality". Hal ini membuat pemahaman arsitektur humanistik Wittkower berbeda dibandingkan Goeffrey Scott. Wittkower menggunakan konsep harmonic proportions bukan anthropomorphic proportions seperti yang diterapkan Scott dalam memenuhi kebutuhan manusia sebagai pengguna. Analisis harmonic proportions Wittkower menggunakan rasio proporsi Vitruvian yaitu 1:10, 1:8 dan 1:6. Rasio-rasio tersebut berasal dari arsitektur dan seni Renaissance yang dapat memberikan perbandingan spasial sebagai dasar rancangan dalam arsitektur humanistik (Irwin, 2015: 4-6).
Tokoh arsitektur humanistik di era modern lainnya adalah Alvar Aalto (1898-1976). Dalam tulisannya berjudul The Humanizing of Architecture (1940), Aalto mengkritisi Rasionalisme arsitektur Humanisme dengan teknologi. Aalto menemukan ketidakseimbangan formula antara fungsi dan bentuk tubuh manusia setelah dikaji dengan aspek-aspek non-fisik seperti aspek psikologis dan kemanusiaan. Aalto menekankan arsitektur hendaknya bisa menjadi penghubung antara manusia dan alamnya. Karya Aalto ini menjadi sangat bernilai karena pemikirannya yang berusaha untuk memanusiakan arsitektur tidak hanya dari aspek fisik melainkan dari aspek non-fisik, seperti psikologis dan sifat-sifat alami manusia (Sudradjat, 2010: 5). Alvar Aalto beasumsi bahwa perkembangan zaman akan memberikan perspektif bagi keinginan manusia sebagai pengguna dalam rancangan bangunan. Mengikuti keinginan yang sebenarnya tidak terlalu berdasar pada kebutuhan inti akan menghasilakan rancangan yang tidak maksimal dalam konteks pemenuhan kebutuhan manusia sebagai pengguna (Hynynen, 2014: 30-32).

\section{Pemahaman Arsitektur Humanistik Pascamodern}

Pada pembahasan pemahaman arsitektur humanistik pascamodern, penulis mengambil salah satu tokoh arsitektur humanis dari Indonesia, yakni Y.B. Mangunwijaya. Menurut Mangunwijaya (1988), "kita berarsitektur agar kita semakin menyatakan dan menyempurnakan ada-diri kita, semakin manusiawi dan semakin manusiawi". Dari pernyataan tersebut dapat dipahami bahwa posisi arsitektur pada dasarnya bertujuan memberikan ruang untuk menyempurnakan sifat manusiawi dari tiap individu. Dalam berarsitektur aspek humanis menjadi pertimbangan dasar bagaimana sifat manusiawi dari soerang manusia dapat berkembang lebih baik. Dapat dikatakan juga bahwasanya adanya arsitektur bertujuan untuk memanusiakan manusia (Stenly, 2015: 177).

Y.B. Mangunwijaya mengatakan bahwa arsitektur adalah media untuk memanusiakan manusia. Keberadaan arsitektur sangatlah dekat dan berkait dengan nilai-nilai, bukan sekadar bangunan wadah. Nilai-nilai kemanusiaan yang dianyam merupakan suatu totalitas, serta berkaitan dengan banyak aspek sejak tahap gagasan desain sampai dengan perwujudan bahkan penggunaannya (Gunawan, 2009: 1-2).

Aspek Humanisme yang menjadi dasar arsitektur salah satunya adalah penggunaan dan pemberdayaan setiap elemen pembentuk arsitektur 
dalam rangka mencapai pemaknaan akan nilai kemanusiaan (Rachmawati, 2010: 105). Dalam hal ini perlu pemberdayaan kualitas fisik, teknik dan bahasa arsitektur yang sesuai dengan konteks yang dituju sehingga dapat sesuai dengan konsep Y.B. Mangunwijaya dalam hal penyempurnaan keberadaan diri dan memanusiakan manusia.

Dasar selanjutnya adalah pendekatan konsep yang merujuk pada manusia sebagai pemakai dari objek arsitektur, baik dalam kapasitasnya secara pribadi maupun kolektif. Manusia tidak hanya diposisikan dan ditinjau sebagai pengguna, tetapi lebih mendalami sari aspek hakekat manusia itu sendiri dan hubungannya dengan aspek-apek kehidupan dan kemanusiaan seperti aspek sosial, budaya, ekonomi, politik, dan lain sebagainya yang selanjutnya akan mempengaruhi output rancangan (Indratno, 2009: 34).

\section{KESIMPULAN}

Dari semua pembahasan di atas penulis menyimpulkan bahwasanya dalam konteks arsitektur humanistik penting bagi seorang arsitek untuk mempertimbangan aspek kebutuhan dasar manusia dalam perancangan arsitektur. Hal ini dapat diadaptasi dari teori hirarki kebutuhan manusia oleh Abraham Maslow. Pemahaman tentang arsitektur humanistik adalah pemahaman konsep arsitektur yang sepenuhnya dikembalikan kepada kebutuhan manusia sebagai penggunanya. Pemahaman arsitektur humanistik telah berkembang di era modern dan era pascamodern. Pemahaman arsitektur humanistik oleh para tokoh-tokoh di masing-masing era mengacu pada pertimbangan aspek kemanusiaan dan kebutuhannya yang dijadikan dasar konsep dalam mendesain sebuah rancangan arsitektur.

\section{DAFTAR PUSTAKA}

Aruma.E.O, Hanachor, Melvis Enwuvesi. (2017) Abraham Maslow's Hierarchy Of Needs and Assessment of Needs In Community Development. International Journal of Development and Economic Sustainability, Vol.5, No.7: 15-27.

Dreki, Mina. (2016). Architecture and Humanism Discuss, diakses: Sabtu, 26 Oktober 2019 melalui :https://www.academia.edu/17592537/Architec ture_and_Humanism.

Goble, Frank G. (1985). Mazhab Ketiga: Psikologi Humanistik Abraham Maslow (terjemahan), Yogyakarta: Kanisius.
Gunawan, Yenny. (2009). Memahami Ruang Mangunwijaya, Seminar Nasional "Jelajah Ruang Nusantara".

Indratno, A, Ferry T (ed). (2009). Penziarahan Panjang Humanisme Mangunwijaya. Jakarta: PT. Kompas Media Nusantara.

Irwin, J. Kirk. (2015). Ratio and the Divine Proportions: Le Corbusier and Rudolf Wittkower, Le Corbusier 50 years later International Congress. pp 1-7.

Lester, David. (2013). Measuring Maslow's Hirarchy of Needs. Psychological Reports: Mental and Physical Health: 15-18.

Makela, Taisto H. (2017). Technology and Humanism. $6^{\text {th }}$ International Alvar Aalto Meeting on Contemporary Architecture. Seinäjoki: Alvar Aalto Academy.

Rachmawati, Murni (2010). Humanisme (Kembali) dalam Arsitektur. NALARs Volume 9 Nomor 2.pp 103-116.

Salado, Alejandro, Nilchiani. Roshanak. (2015). Using Maslow's Hirarchy Theory of Needs to Define Elegance in System Architecture. Conference on Systems Engineering Research (CSER'13). pp 928-936.

Scott, Geoffrey. (1924). The Architecture of Humanism: A Study in the History of Taste, London: Constable and Company Ltd.

Sudradjat, Iwan. (2010). Epistemologi Humanisme baru dalam Arsitektur dan Perencanaan Kota. Seminar Nasional Riset Arsitektur dan Perencanaan "Humanisme, Arsitektur dan Perencanaan" FT UGM Yogyakarta 16 Januari 2010

Yerly Taaluru, Stenly. (2015). Kampung Vertikal Di Sindulang 'Humanisme Dalam Arsitektur, Jurnal Arsitektur Daseng Unsrat Manado, Vol (01). pp 174-181.

Zavei, Sayed avad A P, Jusan. Mahmud Mohd. (2010). Exploring Housing Attributes Selection based on Maslow's Hierarchy of Needs, ASEAN Conference on Environment-Behaviour Studies, Riverside Majestic Hotel, Kuching, Sarawak, Malaysia. pp 311-318. 